\title{
NDT Reliability in the Organizational Context of Service Inspection Companies
}

\author{
Ralf HOLSTEIN*, Marija BERTOVIC**, Daniel KANZLER**, Christina MÜLLER** \\ * DGZfP Ausbildung und Training, Berlin, Germany \\ ** BAM Bundesanstalt für Materialforschung und -prüfung, Berlin, Germany
}

\begin{abstract}
Much of NDT-Reliability-Research in the past was done in the field of two high risk industries: (atomic) power plants and aircrafts. The responsible organizations have been well aware of the risks and founded projects to understand and optimize critical steps during production, operation and maintenance. But the use of NDT is not limited to these two fields. The risks during operation of chemical plants, trains or windmills are different from the area above but evident. The coverage by legal regulations is relatively low. Instead of this owner responsibility, product liability and financial issues are the driving forces to do inspections and to use non-destructive testing. The different targets and financial issues are influencing the practice of NDT-inspections. A survey of this practice and its results are shown.
\end{abstract}

\section{Introduction}

Many traditional costumers using services in the field of Non-Destructive Testing (NDT) simply like to buy the pure inspection of a technical component. Their focus if often price and time and they don't know much about the influencing factors on the reliability of such services. And how could they know? The majority of publications in the field of NDT deals with the efficiency of methods and equipment.

In high risk areas like Aerospace Industries and Nuclear a sensitivity for NDTreliability is visible. As a result of the investigation of incidents these industries and their authorities formulated standards and rules, initiated a systematic scientific research.

The scientific research has shown that the reliability of NDT is depending on three main factors: Intrinsic Capability, Application and the Human. A fourth factor was added during the 4th European-American Workshop on Reliability of NDE in Berlin 2009. Babette Fahlbruch showed a general model of the organizational environment: 


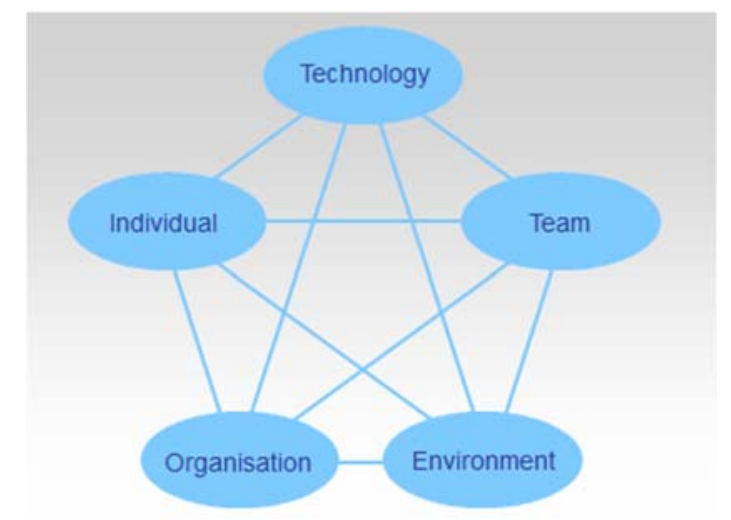

Pic. 1. B. Fahlbruch; Integrating Human Factors in Safety and Reliability Approaches (1)

Following this model it seemed logical that the organizational frame should be added in to the model for the reliability of NDT.

But how can one describe the organizational frame in the field of NDT-services? What are the processes? This was the aim of this paper.

\section{Methods}

Basis of the work was to study existing publications in the field of NDT reliability. In parallel papers in the field of service processes where analyzed. A third source was an actual study of the German "Fbb Institut Nürnberg" (2) concerning the vocational training of material testers in Germany, the structure of their work tasks and the requirements of German employers.

On the basis of theses information a model about the processes regarding organization of NDT Services was developed.

\section{Results}

When analyzing the driving forces for a customer to order NDT-services it seems that

- Legal Requirements

- Owner responsibility

- Product liability

- Financial issues

are the major reasons. (3)

Following Fahlbruch et.al. (4) the precautions for the safety of technical systems could be divided in three major fields:

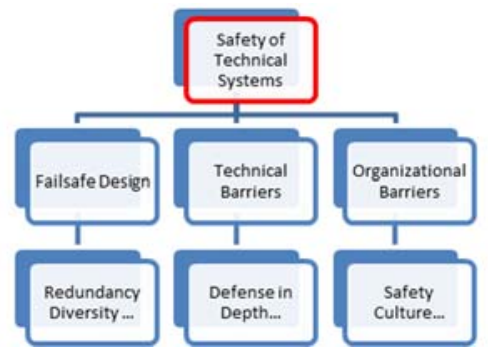

Pic. 2: Customer Side: Safety Approach 
In every field NDT could be a need to control the integrity of the components, during production or periodically. Questions arise how NDT delivered by an external service fits in to the safety culture approach? The International Atomic Energy Agency defines a saftey culture as: "The assembly of characteristics and attitudes in organizations and individuals which establishes that, as an overriding priority, protection and safety issues receive the attention warranted by their significance." (5)

For the NDT-company offering such a service the business aspect of the work is the main driving force. (6) Additional motivation for the employees is to serve public safety and to have an interesting work task.

But it seems difficult to influence the attitudes and characteristics of an external NDT-operator who - worst case - is daily changing his work site and inspection task, in a sufficient manner. Organization and sensitive supervision could be the only answer to this question.

What information is required to give the service provider a chance to deliver a reliable NDT-result?

The main human-related elements (7) beside intrinsic capability and application factors are stated as:

- Operator Selection Process

- Information Processing and Decision Making

- Motivation

- Training

- Experience

- Procedures

It seems clear that the process of providing an NDT-service should be organized in a manner that takes all these factors in to account. But what are the involved persons on customer and provider side? Which informations are needed and which are really exchanged?

For further investigation it was decided to separate three different processes:

- Business Process (Bid, Contract, Purchasing...)

- Information Process (Time, Place, Criteria, Procedures, Reporting...)

- Delivery Process (Equipment, Operators, Reports ...)

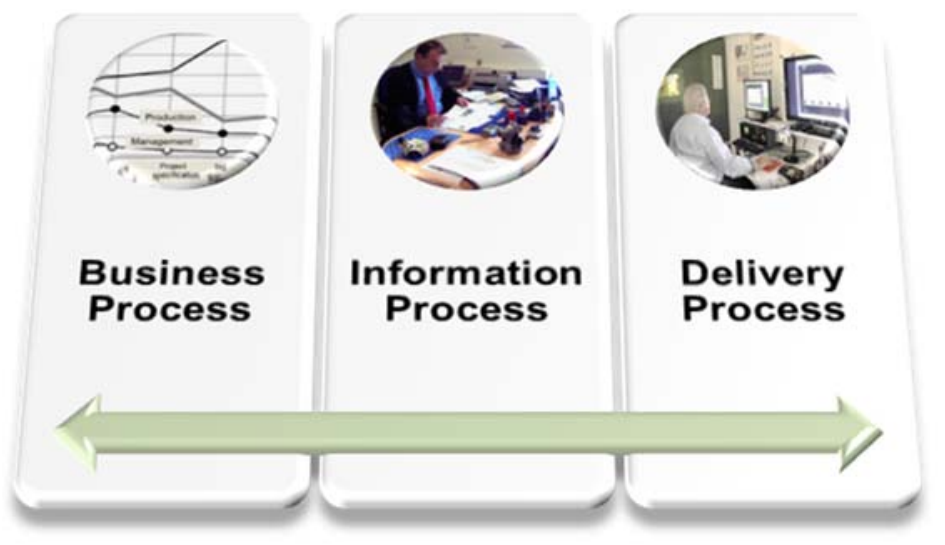

Pic. 3: The Process Modell 


\section{A) Business Process}

Basis and often starting point of every NDT-service is an agreement/contract about the financial side of the job. On the side of the Service-provider this process is mainly handled by the sales persons if not by the management. On the costumer side the Business Process is mainly handled by a purchasing department or function in the organization of the customer.

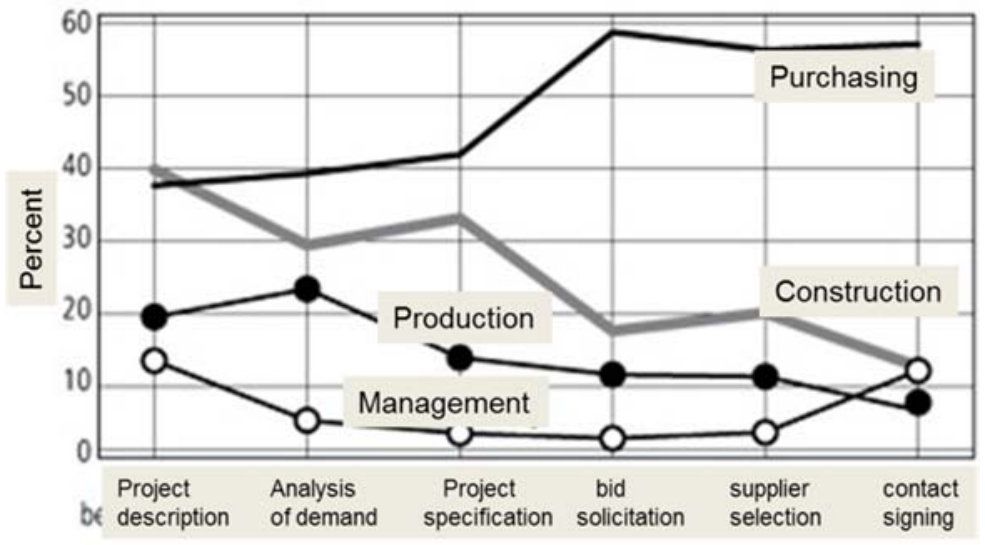

Pic. 4. Involved parties in various phases of the purchasing process [modified from 8]

The influence of departments with technical competences is limited and it seems that the required information influencing mainly the inspection reliability could not be gained during this process.

\section{B) Information Process}

Both parties need different kinds of information long before the NDT-service is delivered. The exchange requires technical competent partners on both sides.

For the customer it is important to know:

- Capability and Reliability of NDT-Method

- that the services of the provider are able to fulfil these requirements

- Required work environment for reliable NDT

- How to interpret the outcome of NDT

- Traceability of NDT

The service provider needs to know:

- Material, Processing, Task and History of Component

- Known defects on comparable Components

- Work Environment (Responsibilities, Access, Conditions, Labor Safety)

- Test Procedure (Method, Technique, Areas, Criteria)

- Reporting Process of Result and Required Actions

These informations are essential for a reliable and dependable inspection result. They influence also the costs and the time schedule. In an ideal work flaw all informations 
are available before a contract is signed. The less is known before the delivery of the service the more tasks the operator has to handle on the inspection site.

The British Health and Safety Executive stated in a report 2008: "Apart from carrying out the inspection itself, the role of operators in an inspection should be limited to verifying the adequacy of the arrangements for safety, access and plant condition. The preparation for the inspection and the provision of an adequate and appropriate inspection procedure is the responsibility of the client and/or NDT organisation as appropriate" (9)

Missing information about the inspection task also prevents that the serviceprovider could select the optimal equipment and team.

\section{C) Delivery Process}

The delivery process is very often the visible core of the service and gets most attention from both parties. A team of inspectors is arriving at the scene bringing nice equipment to life and operating full of confidence.

But this is only a picture from outside. Beside these practical activities some thoughts must be spend to the following items.

Before the operator can start his inspection job, he needs to check:

- Do I have all necessary Information?

- Are Component, Equipment and Team prepared for the Inspection?

Beside the inspection a lot of events have to be taken in to account:

- How do I handle unexpected Events (If things go wrong - Decision Chain)?

- What do I do with the Inspection Result: Documentation and further Actions?

- How do I handle a Repetition of the Inspection, if required?

(Repair, Exchange, Procedure Problems)

And the job is not done with the delivery of the final report. After collecting all equipment and leaving the (clean) site, two tasks are waiting.

- Finalization of Business Process:

Information to the accountants that the job was done, about used resources and working time.

- Knowledge Management: Report to Supervisors about

Experience made, Problem Discussion, future Improvement.

For the management it is time to report to the customer about the inspection result, recommendations and to ask if the expectations where fulfilled.

\section{D) Process environment}

Finally the question arises in which environment the three processes are running. Following the results of Fahlbruch et al different cultures, rules and requirements influence them from outside. 


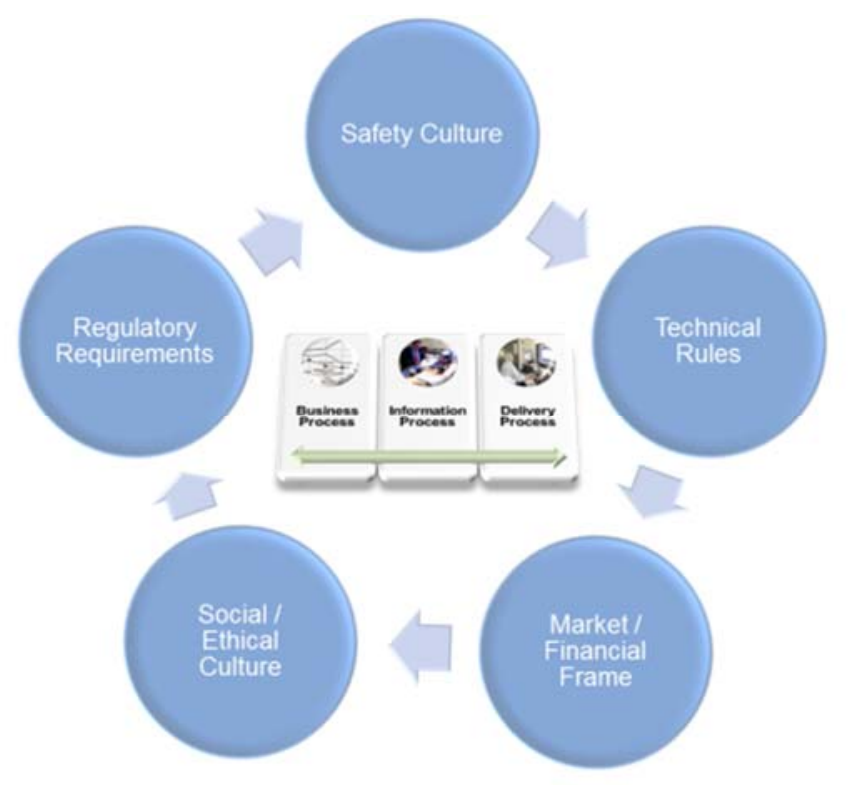

Pic. 5: Process Environment

How the environment can have a negative influence on the processes connected with NDT-inspections could be read in different sources.

The British HSE stated: "Feedback from contributors to the project indicated that an organisational culture can predominate in which inspection is regarded simply as a statutory or contractual necessity rather than as a valuable process which can help avoid plant failures."(9)

A market study on innovation on the service inspection marked in Germany and the Netherlands formulated: “The fact that many people in the NDT sector don't know how their results are being used also contributes to an overall picture where value is insufficiently expressed." (10)

But apart from these negative examples NDT is mainly performed in an environment where a good inspection and reliable results are daily practice. The author knows this from many visits on work places of inspectors and daily talks with participants on NDT-courses during 25 years of experience in the sector.

\section{Discussion}

The fbb-Institute performed in the years 2011 and 2012 a study about the key competences of an NDT-Inspector in Germany. They described six main fields of the work:

- Preparation of the Inspection Task

- Preparation of Testing Equipment

- Preparation of Work Place

- Performance of the Inspection

- Proper Leaving of the Work Place (including Disposal)

- Final Documentation

(2)

This can be taken as the core of the work of an NDT-Inspector. The company hiring the inspector is responsible to form an organizational environment in which the inspector can do a proper job. 
Former studies have shown that organization is a factor influencing the reliability of NDT. (1)

The model of visualizing the organizational factor through the processes Business, Information and Delivery seems to be helpful. It makes it possible to identify process owners, involved parties and documentation requirements.

The incorporation of such processes in the daily work of inspection providers has the same importance like good equipment and well trained inspectors.

Further work is needed to proof the validity and usefulness of the process model in the practice of service inspection providers.

\section{References}

[1] FAHLBRUCH, B. Integrating Human Factors in Safety and Reliability Approaches. In: Deutsche Gesellschaft für Zerstörungsfreie Prüfung, ed. 4th European American Workshop on Reliability of NDE. June 24-26, 2009, Berlin, Germany. Berlin: DGZfP, 2009.

[2] FBB. Untersuchung zu neuen und modernisierten Berufsprofilen und einem Berufsgruppenprinzip für prüftechnische Berufe. Abschlussbericht, 15 May. 2012.

[3] BAUER, C. O. Qualitätssicherung durch Zertifikate - läßt sich Haftung delegieren? [online]. ZfPZeitung. 1997. Available from: http://www.ndt.net/article/dgzfp/dach59/bauer/bauer.htm.

[4] FAHLBRUCH, Babette, Markus SCHÖBEL, and Juliane DOMEINSKI. Sicherheit. In: Petra BadkeSchaub, ed. Human Factors. Psychologie sicheren Handelns in Risikobranchen : mit 17 Tabellen. Heidelberg: Springer, 2008, pp. 19-35.

[5] INTERNATIONAL ATOMIC ENERGY AGENCY. Safety culture - a Report. Vienna: International Atomic Energy Agency, 1991. Safety series. 75-INSAG-4. 92-0-123091-5.

[6] BEUSHAUSEN, Willi. Das Verhältnis von Dienstleister und Auftraggeber [online]. ZfP-Zeitung. 1997, 59. Available from: http://www.ndt.net/article/dgzfp/dach59/beushaus/beushaus.htm.

[7] BERTOVIC, M., B. FAHLBRUCH, C. MÜLLER, J. PITKÄNEN, U. RONNETEG, M. GAAL, D. KANZLER, U. EWERT, and D. SCHOMBACH. Human Factors Approach to the Acquisition and Evaluation of NDT Data: Examples of Experiments,. 18th World Conference on Nondestructive Testing, 16-20 April 2012, Durban, South Africa.

[8] BACKHAUS, Klaus. Industriegütermarketing. 7., erw. und überarb. Aufl. München: Vahlen, 2003. Vahlens Handbücher der Wirtschafts- und Sozialwissenschaften. 9783800628865.

[9] HEALTH AND SAFETY EXECUTIVE. Programme for the assessment of NDT in industry. PANI 3. Prepared by Serco Assurance. Risley, UK, 2008.

[10] WASSINK, CASPER HARM PHILIP. Innovation in NDT. Delft, 2012. 